\title{
Pharmacognostic and phytochemical investigation of young leaves of Triticum aestivum Linn.
}

\author{
${ }^{*}$ Gaurav Jain, Ameeta Argal \\ Department of Pharmaceutical Sciences, Bhagwant University, Ajmer, Rajasthan, India
}

\begin{abstract}
The aim of the work is to perform the pharmacognostic study of the leaves of plant Triticum aestivum Linn., Family Poaceae, commonly known as 'Wheatgrass'. It is cultivated on large scale all over India and also occasionally cultivated in garden. For the present study samples of the Wheatgrass leaves were collected over a specific period of nine days. The drug was cultivated with specific type of hybrid seeds obtained from most reputed institution of India and were scrupulously analysed. For standardization of the herbal drug morphological, phytochemical, physicochemical and microscopical examination was done. The leaves grown were found to be lax, cauline, flat, 0.6 to 0.25 inches $(4$ to $6 \mathrm{~mm}$ ) wide, $6-9$ inches long and green in color. The chemical compositions of the leaves are proteins, flavonoids, alkaloids, glycosides, terpenoides, saponins, fibers, tannins and phenolic compounds. The specific variety of seeds, specific time of collection made it more specific to be used for further pharmacological studies.
\end{abstract}

Key Words: Triticum aestivum grass, physicochemical, microscopical examination, phytochemical screening, wheatgrass, standardization.

\section{INTRODUCTION}

Scientific research is increasingly confirming what was known to our ancestors from experience. While plants continued to provide us pleasure with their beauty (color and fragrance) and enhance the taste of our food by their flavor, we seemed to have become moreish. Young cereal plants were valued in ancient times. It has been said that people in the ancient Middle East ate the green leaf tips of the wheat plant as a delicacy. Bottled, dehydrated cereal grass has been a popular food supplement for people in the United States since the early 1930s. The work done here is a step forward in bringing a more detailed study of the drug and to be able to answer the hidden causes of remarkable drug achieving its activity from a food supplement to a more promising drug for many dreaded diseases. Our literature review reveals that the plant Triticum aestivum Linn belonging to the family Poaceae can be used for different liver ailments, to help prevent cancer, tooth decay, skin problems such as eczema and psoriasis (Kartesz, 1989). It is also claimed to reduce hair from graying, improves digestion, reduces high blood pressure as it enhances the capillaries, support the growth of lactobacilli and can remove heavy metals from the body (Lai et al., 1977; Lai et al., 1980; Locniskar, 1988; Meyerowitz, 1999). It is found to improve hematological toxicity related to chemotherapy in breast cancer patients, chemoprevention of mouse skin carcinogenesis induced by DMBA and croton oil in association with oxidative status, it reduces the frequency and requirement of blood transfusions in thalassemia major (Marwaha et al., 2004; Sela et al., 2007; Singh et al., 2010; Arya et al., 2011).

Various useful attempts have been made for the pharmacognostic study of the drug (Kumar et al., 2010; Pallavi et al., 2011). This work deals with the ninth day young wheatgrass when the plant is at its full nutritional

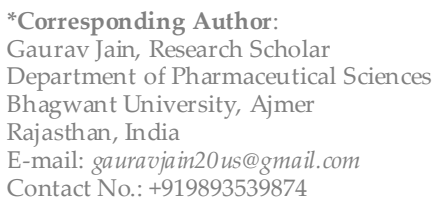

power, called the jointing stage (figure 1 and 2) and has tried to explore the microscopical elucidation with more descriptive interpretation and besides this the various distinct longitudinal sections have been used to system atize pharmacognostic evaluation of wheatgrass. The present work is emphasized on the ninth day young wheatgrass and all the studies are standardized at that specific time and age of collection as well as the specific variety of hybrid seeds was collected from the most renowned research institution of India. It has already been proved that the age of the plant play a keen role in efficacy of the plant valuation (Kohler, 1943). Hence it is an important attem pt to increase the efficacy of the plant.

\section{MATERIALS AND METHODS}

Procurement and authentication of the plant material The Wheatgrass seeds for the research were purchased from Breeder Seed Production Unit Field crops, Department of Plant Breeding and Genetics, Jawahar Lal Nehru Krishi Vishwavidyalaya, Krishinagar, Jabalpur M.P. and the release order number was obtained. The whole plant of Triticum aestivum was collected in the month of December and authenticated at Safia college of Science Bhopal, Madhya Pradesh. The herbarium of the plant was prepared and the voucher specimen number 236/BOT/SAFIA/2011 was obtained.

\section{Preparation of Triticum aestivum powder}

The ninth day grass of Triticum aestivum was cultivated, collected and chopped with the help of knife. It was dried in shade and then powdered with a mechanical grinder. The powder was passed through sieve no.40 and stored in a labeled air tight container for further studies.

\section{Macroscopic studies}

The fresh herb was subjected to macroscopic studies which comprised of organoleptic characters of the drugs viz. color, odour, appearance, leaves size, taste and texture (table 1). 


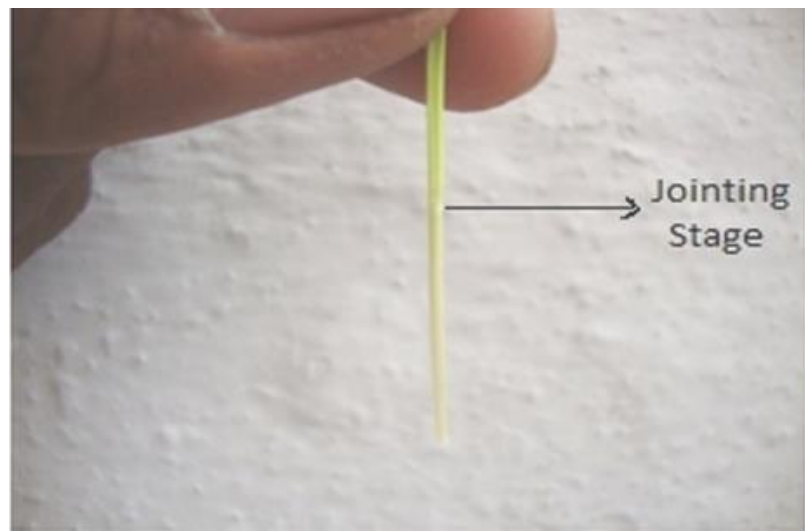

Figure 1: Wheatgrass plant at jointing stage.

\section{Microscopic studies}

Qualitative microscopic evaluation was carried out by taking transverse and longitudinal sections of fresh leaves. Free hand sections of the fresh leaves were boiled with chloral hydrate to remove all the coloring matter. The sections were transferred and mounted (gly cerine) on a slide and a cover slip was placed over it (Trease and Evans, 1996; Mukherjee, 2010).

\section{Physicochemical studies}

Physicochemical studies include ash value and extractive value to determine the quality and purity of the powder of plant of Triticum aestivum. (Indian Pharmacopoeia, 1996; WHO, 2002)

\section{Ash values}

Total ash value

Accurately weighed $2 \mathrm{gm}$ of air dried sample were taken in a tarred silica dish and incinerated at a temperature not exceeding $450^{\circ} \mathrm{C}$ until free from carbon, then cooled and weighed. Percentage of ash value was calculated with reference to the crude air dried drug.

\section{Acid insoluble ash}

Ash was boiled with $25 \mathrm{ml}$ of $2 \mathrm{M} \mathrm{HCl}$ for $5 \mathrm{~min}$, insoluble matter was collected in a Gooch crucible in an ash less filter paper, washed with hot water, ignited, cooled in desiccators and weighed. Percentage of acid insoluble ash was calculated with reference to the air dried drug.

\section{Water soluble ash}

Ash was boiled for $5 \mathrm{~min}$ with $25 \mathrm{ml}$ of water, insoluble matter was collected in a Gooch crucible in an ash less filter paper, washed with hot water and ignited for $15 \mathrm{~min}$ at a temperature not exceeding $450^{\circ} \mathrm{C}$. Weight of insoluble matter was subtracted from the weight of the ash; the difference in weight represents the water soluble ash. Percentage of water soluble ash was calculated with reference to the air dried drug.

\section{Extractive Values}

\section{Water soluble extractives}

$4 \mathrm{gm}$ of air dried plant material was macerated with $100 \mathrm{ml}$ of water in a closed flask, shaking frequently during the first $6 \mathrm{hr}$ and allowed to stand for $18 \mathrm{hr}$. Thereafter it was filtered rapidly taking precaution against loss of water. $25 \mathrm{ml}$ of filtrate was evaporated to dryness in a tarred flat bottom shallow dish dried at $105^{\circ} \mathrm{C}$ and weighed. Percentage water soluble extractive was calculated with referen ce to the crude air dried plant material.

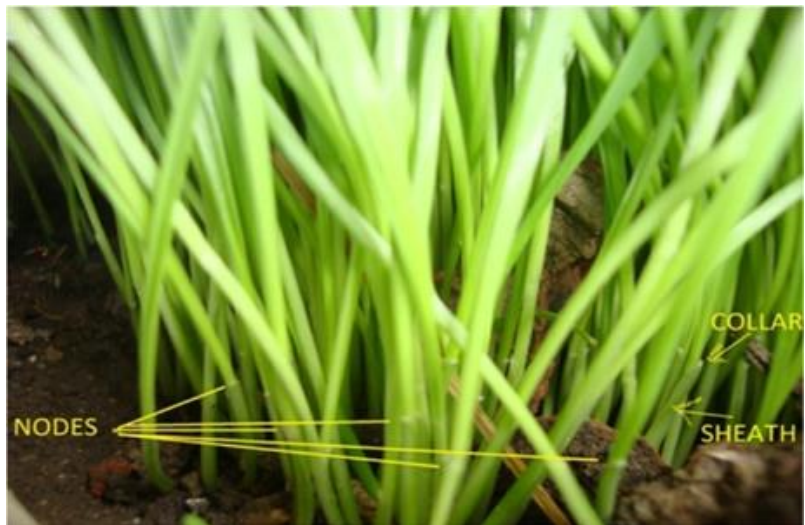

Figure 2: Wheatgrass plant with nodes, collar and sheath.

\section{Alcohol soluble extractives}

$4 \mathrm{gm}$ of air dried plant material was macerated with $100 \mathrm{ml}$ of methanol in a closed flask, shaking frequently during the first $6 \mathrm{hr}$ and allowed to stand for $18 \mathrm{hr}$. Thereafter it was filtered rapidly taking precaution against loss of methanol. $25 \mathrm{ml}$ of filtrate was evaporated to dryness in a tarred flat bottom shallow dish dried at $105^{\circ} \mathrm{C}$ and weighed. Percentage methanol soluble extractive was calculated with reference to the crude air dried plant material.

\section{Preliminary phytochemical screening}

The alcoholic and aqueous extracts of Triticum aestioum were subjected to preliminary phytochemical screening to determine the presence of phytoconstituents. Screening was carried out on both the Triticum aestivum extracts to determine the active principles or secondary plant constituents. Two milliliters of each extract were measured into a test tube for each of the tests and concentrated by evaporating the extract in a trough. Tests were carried out for carbohydrates, reducing sugars, tannins, polyphenols, lipids, flavonoids, ketones, alkaloids, steroids and triterpenes.

\section{Alkaloids}

Mayer's test. Alkaloids gave cream color precipitate with Mayer's reagent (potassium mercuric iodide solution). Dragandroff's test. Alkaloids gave reddish brown precipitate with Dragandroff's reagent (potassium bismuth iodide solution).

Wagner's test. Alkaloids gave a reddish brown precipitate with Wagner's reagent (solution of iodine in potassium iodide).

Hager's test. Alkaloids gave yellow color precipitate with Hager's reagent (saturated solution of picric acid).

\section{Glycosides}

General test for the presence of glycosides

Part A: $200 \mathrm{mg}$ of the drug was extracted by warming in a test tube with $5 \mathrm{ml}$ of dilute $(10 \%)$ sulphuric acid on a water bath at $100^{\circ} \mathrm{C}$ for $2 \mathrm{~min}$, centrifuged, pipetted off supernatant. The acid extract was neutralized with $5 \%$ solution of sodium hydroxide (noting the volume of sodium hydroxide added). $0.1 \mathrm{ml}$ of Fehling's solution A and then $B$ were added until solution became alkaline (tested with $\mathrm{pH}$ paper) and heated on a water bath for 2 min. Noted the quantity of red precipitate formed and compare with that formed in Part-B. 
Table 1: Macroscopic evaluation of Triticum aestivum.

\begin{tabular}{ccc}
\hline Sl. & Parameter & Observation \\
\hline No. & Color & Dark green. \\
1 & Faintly characteristic. \\
2 & Odour & Lanceolate leaves, without cross venation. \\
3 & Appearance & Lanch \\
4 & Leaves size & $4-6$ mm wide and 6-9 inches long. \\
5 & Taste & Slightly sweet. \\
6 & Texture & Soft. \\
\hline
\end{tabular}

Table 2: Ash values of Triticum aestivum grass.

\begin{tabular}{ccc}
\hline Sl. & Ash value & \% W/W \\
No. & Total ash & 15.1 \\
\hline 1 & Acid insoluble ash & 5.3 \\
2 & Acid soluble ash & 4.9 \\
3 & Water insoluble ash & 12.5 \\
4 & Water soluble ash & 3.1 \\
5 & & \\
\hline
\end{tabular}

Table 3: Extractive values of Triticum aestivum grass in following solvents.

\begin{tabular}{ccc}
\hline Sl. & Physicochemical parameters & \%W/W \\
No. & Water soluble extractive value & 20 \\
\hline 1 & Methanol soluble extractive value & 25 \\
2 & Benzene soluble extractive value & 15 \\
3 & Choloroform soluble extractive value & 5 \\
4 & Petroleum ether soluble extractive value & 10 \\
5 & &
\end{tabular}

Table 4: Phytochemical constituents found in methanolic and aqueous extract.

\begin{tabular}{cccc}
\hline $\begin{array}{r}\text { Sl. } \\
\text { No. }\end{array}$ & Experiment & $\begin{array}{c}\text { Aqueous } \\
\text { Extract }\end{array}$ & $\begin{array}{c}\text { Methanolic } \\
\text { Extract }\end{array}$ \\
\hline 1 & Alkaloids & - & + \\
2 & Glycosides & - & + \\
3 & Tannins \& & + & + \\
4 & Phenolic comp. & + & + \\
5 & Saponins & + & + \\
6 & Flavanoids & + & - \\
7 & Carbohydrates & - & + \\
8 & Steroids & - & + \\
\hline
\end{tabular}

(+)Present, (-) Absent

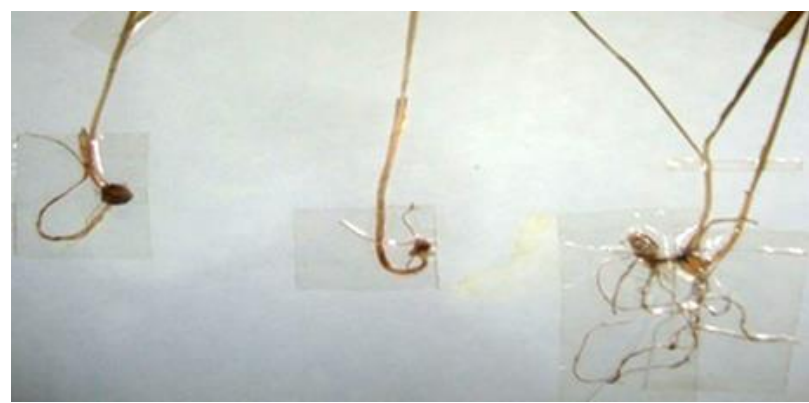

Figure 3: Wheatgrass roots at ninth day.

Part B: $200 \mathrm{mg}$ of the drug was extracted using $5 \mathrm{ml}$ of water instead of sulphuric acid. After boiling, equal volume of water to that of sodium hydroxide used in the above test was added. 0.1ml of Fehling's solution A and B were added until solution became alkaline (tested with
$\mathrm{pH}$ paper) and heated on water bath for $2 \mathrm{~min}$. The quantity of red precipitate formed was noted.

The quantity of precipitate formed in Part-B was compared with that formed in Part-A. If the precipitate in Part-A was greater than in Part-B then Glycoside may be present. Since Part-B represents the amount of free reducing sugar already present in the crude drug. Whereas Part-A represents free reducing sugar plus those related on acid hydrolysis of any sides in the crude drug.

Saponin glycosides

Froth test: Placed $1 \mathrm{ml}$ solution of drug in water in a semi micro tube, shaken well and noted the stable froth.

\section{Anthraquinone glycosides}

Borntrager's test: Boiled test material with $1 \mathrm{ml}$ of dilute sulphuric acid in a test tube for $5 \mathrm{~min}$ (anthracene glycosides were hydrolyzed to aglycone and sugars by boiling with acids) centrifuged or filtered while hot (if centrifuged hot, the plant material can be removed while anthracene aglycones are still sufficiently soluble in hot water, they are however insoluble in cold water), pipetted out the supernatant, cooled and shaked with an equal volume of dichloromethane (the aglycones will dissolve preferably in dichloromethane) separated the lower dichloromethane layer and shaked with half its volume with dilute ammonia. A rose pink to red colour was produced in the ammonical layer (aglycones based on anthroquinones give red colour in the presence of alkali).

Modified Borntrager's test: Boiled $200 \mathrm{mg}$ of the test material with $2 \mathrm{ml}$ of dilute sulphuric acid, $2 \mathrm{ml}$ of $5 \%$ aqueous ferric chloride solution for $5 \mathrm{~min}$ and continued the test as above. As some plant contain anthracene aglycone in a reduced form, ferric chloride was used during the extraction, oxidation to anthroquinones took place, which showed response to the Borntrager's test.

\section{Cardiac glycosides}

Keller Killiani test (Test for deoxy sugars): Extracted the drug with chloroform and evaporated it to dryness. $0.4 \mathrm{ml}$ of glacial acetic acid was added which contained a trace amount of ferric chloride and was transferred to a small test tube. Carefully $0.5 \mathrm{ml}$ of concentrated sulphuric acid was added along to the side of the test tube, blue colour appeared in the acetic acid layer.

Tannins and phenolic compounds

Gelatin test. Extract with $1 \%$ gelatin solution containing $10 \%$ sodium chloride gave white precipitate.

Ferric chloride test. Test solution gave blue green color with ferric chloride.

Vanillin hydrochloride test. Test solution when treated with few drops of vanillin hydrochloride reagent gives purplish red color.

Heary metal test. Tannins got precipitated in the solution when treated with heavy metals.

Alkaline reagent test. Test solution with Sodium hydroxide solution gave yellow to red precipitate within short time.

Mitchell's test. With iron and ammonium citrate or iron and sodium tartarate, tannins gave a water soluble iron tannin complex, which was insoluble in solution of ammonium acetate.

Flavonoids

Shinoda test: (Magnesium hydrochloride reduction test). To the test solution, few fragments of magnesium ribbon were added and concentrated hydrochloric acid was 


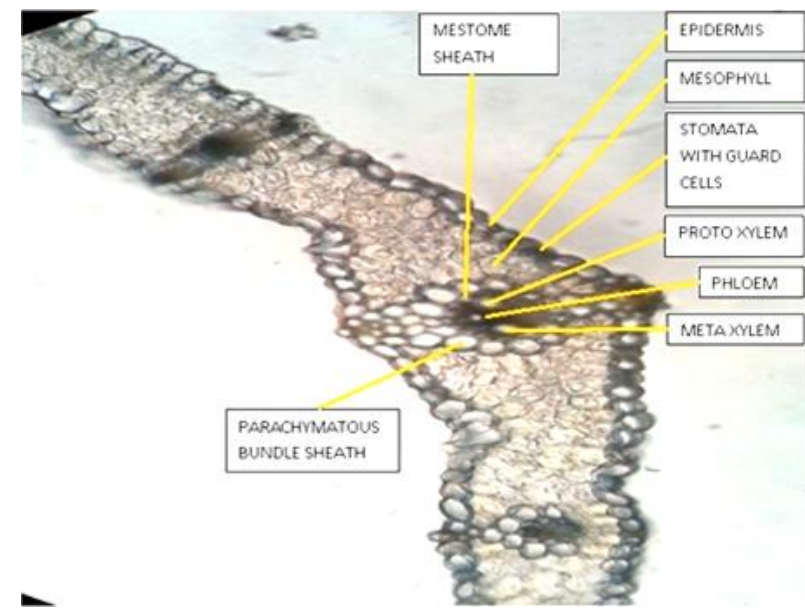

Figure 4: T.S. showing epidermis, vascular tissue and mesophyll.

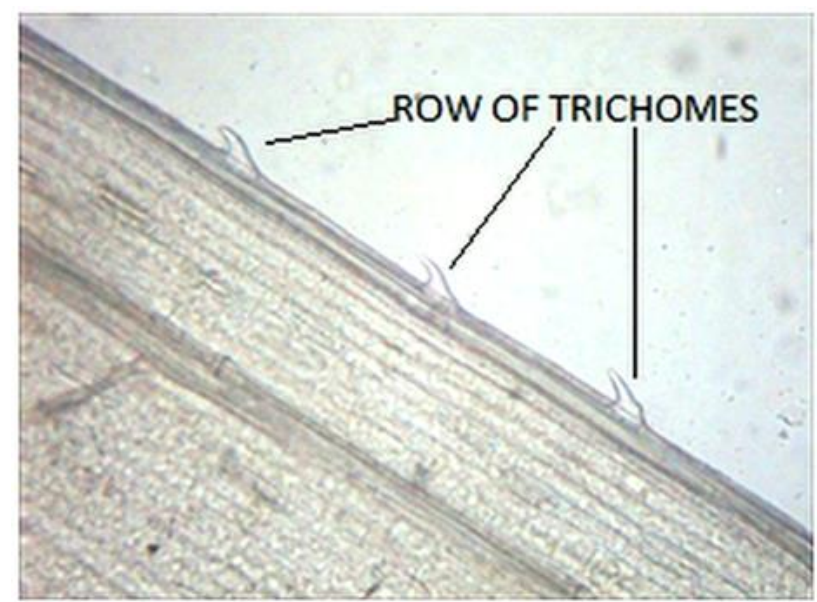

Figure 6: L.S. showing row of Trichomes.

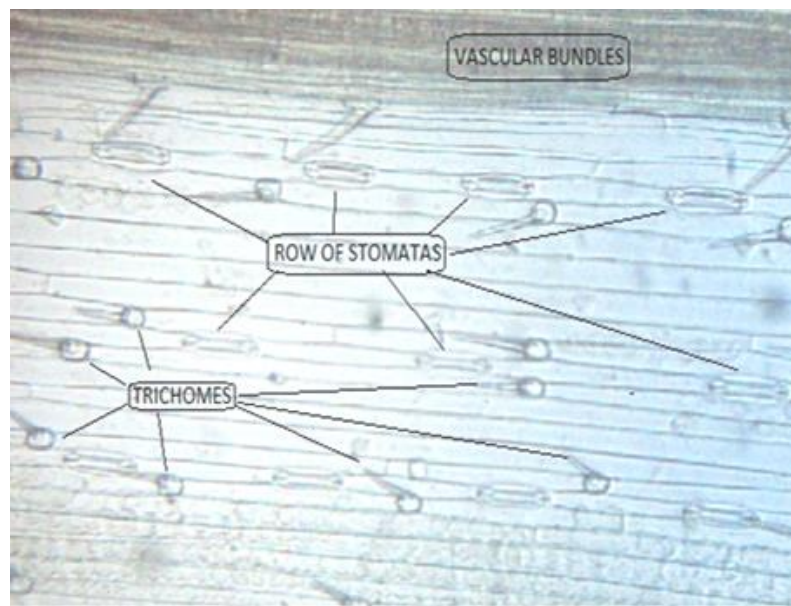

Figure 8: L.S. showing arrangement of stomatas, trichomes and vascular bundles in leaves.

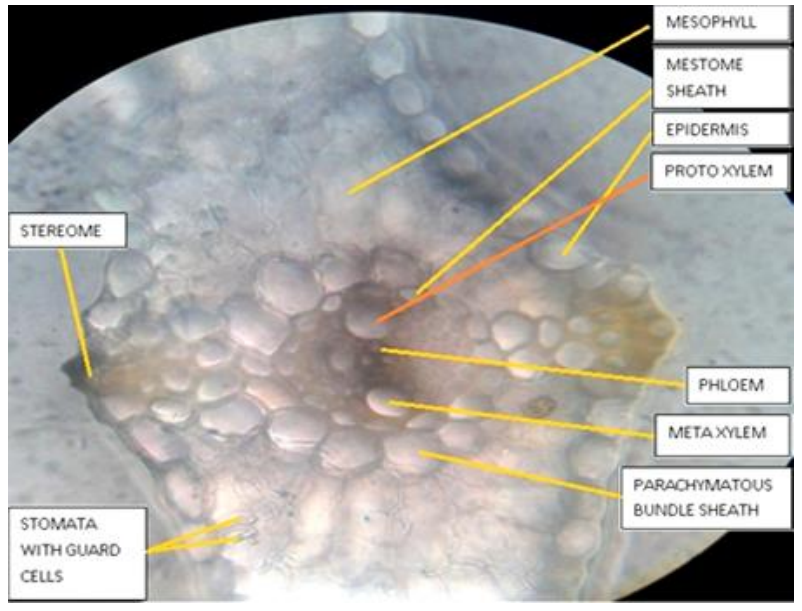

Figure 5: T.S. showing arrangements of vascular bundles.

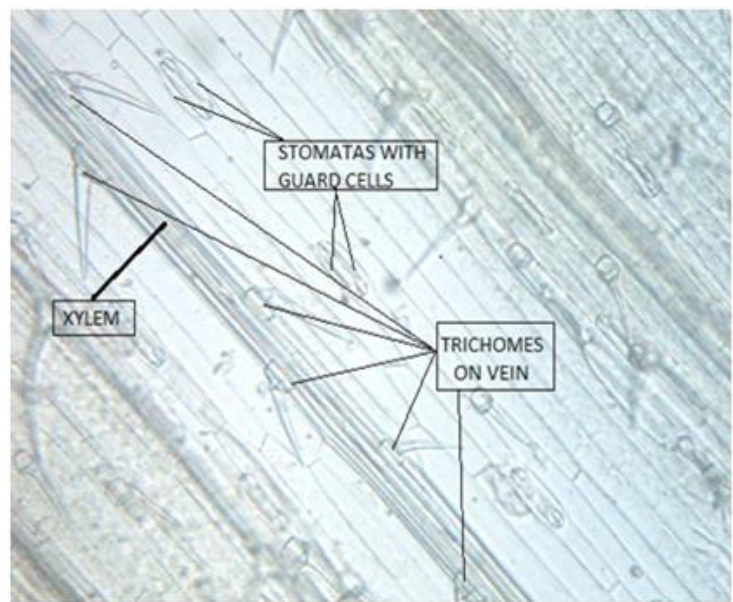

Figure 7: L.S. showing arrangement of stomatas, xylem and trichomes.

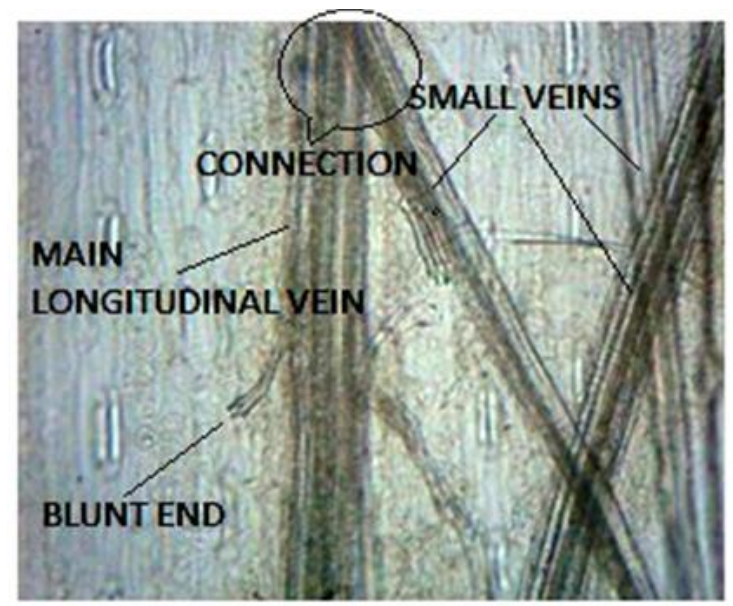

Figure 9: L.S. showing showing connection and blunt end of different veins. 
added drop wise, pink scarlet, crimson red or occasionally green to blue color appeared after few minutes.

Zinc hydrochloride reduction test. To the test solution, a mixture of zinc dust and concentrated hydrochloric acid were added. Red color obtained after few minutes.

Alkaline reagent test. To the test solution, few drops of sodium hydroxide solution were added. An intense yellow color was formed, which turned colorless on addition of few drops of dilute hydrochloric acid, indicated presence of Flavonoids.

\section{Proteins and amino acids}

Millons test. Test solution was mixed with $2 \mathrm{ml}$ of Millons reagent (mercuric nitrate in nitric acid containing traces of nitrous acid), white precipitate appeared, which turned red upon gentle heating.

Ninhydrin test. Amino acids and Proteins when boiled with $0.2 \%$ solution of Ninhydrin (indane 1, 2, 3 trione hydrate), violet colour appeared (Kokate et al., 2003; Khandelwal, 2010).

\section{RESULTS AND DISCUSSION}

The plant of Triticum aestivum is an indigenous herb which was chosen for this study. It belongs to the family Poaceae. The scanty availability of information on this plant facilitates the study on it since ages this plant is being used for its medicinal value. Various useful attempts have been made for the pharmacognostic study of the drug. This attempt is made to study in detail the transverse as well as the longitudinal section of the drug so that the specific variety of the drug can be identified and collected at the specific time for its various important chemical constituents so that the drug can be used effectively to its full potential. The study was divided in two parts:-

- Pharmacognostical studies

- Phytochemical screening

\section{Pharmacognostical Studies}

\section{Macroscopic evaluation}

The macroscopic characters are useful in quick identification of plant material and also serve as a vital standardization parameter. Organoleptic evaluations of Triticum aestivum herb were reported in table 1. Leaves are acicular needle shaped, simple, lanceolate, parallel venation, margin is entire, even, smooth throughout with pubescent surface and subacute apex. It has sheath and collar with no ligule as shown in figure 1 . Stems, called culms grow up from the base of the plant. It is hollow and rigid, except at the nodes. It is rough and hairy surface with prominent and distinct nodes and internode as shown in figure 2. Roots are tortuous, fibrous, adventitious and many lateral roots shown in figure 3.

\section{Microscopic evaluation}

There are three characteristic features in the transverse section of wheatgrass leaf i.e. epidermis, vascular tissue and mesophyll. The epidermis encloses the mesophyll, which is contravened at intervals by the vascular tissue. The vascular tissue and mesophyll are organized in alternately running parallel with the axis of the leaf (figure 4). The epidermis is like the bulliform cells and are long cylindrical cells with a smaller diameter alternating in a regular manner with stomata. Each stoma is made up of two characteristic shaped guard cells and has two associated accessory cells (figure 5). They are more on the adaxial surface and are more densely distributed towards the tip (figure 5,6). Short, unicellular hairs occur mainly over the veins and on either side of the row of stomata (figure 7). The mesophyll cells are of a complex lobed shape. When viewed in transverse section, the subepidermal cells of the mesophyll are elongated and in longitudinal section, the lobed nature of these cells is apparent. They consist typically of tightly packed xylem and phloem tissues surrounded by a parenchymatous or fibrous sheath. Both xylem and the phloem contain living parenchyma cells as well as their characteristic transporting conduits. The phloem is abaxial to the xylem and in the larger bundles consists of regularly arranged sieve tubes and companion cells. The xylem has two large, prominent xylem vessels between which are smaller metaxylem vessels and fibres. Adaxial to the metaxylem, there is an area of disrupted protoxylem. The conducting elements are surrounded by an inner (mestome) sheath and an outer (parenchyma) sheath. The cells of the mestome sheath are small and thick-walled and are without chloroplasts. Those of the outer bundle sheath are large and thin-walled and contain chloroplasts (figure 5).

The longitudinal section showed many elongated rectangular cells joined end to end making a chain like formation arranged parallel to the long axis. In a row are arranged alternately characteristic stomatas, these rows are arranged after every five to six adjoining rows of rectangular cells (figure 8). The small veins that interconnect the main longitudinal veins consist only of a single sieve tube and xylem vessel and two files of parenchyma cells. They pass through the mestome and parenchyma sheaths and connect directly with the metaxylem and metaphloem of the main bundles. The cells of the bundle sheaths are elongated with blunt ends (figure 9). The walls of the mestome sheath are lignified and sometimes the wall adjacent to the conducting elements is thicker than the other walls of the cell (figure 6). The complex fine structure of the mestome sheath is important in regulating the transport of water and solutes. The longitudinal section also showed characteristic unicellular trichomes arranged in a row (figure 5). They are more densely arranged on the veins (figure 7 ). Trichomes are broad at the base and pointed at the end (figure 6).

\section{Ash Values}

The physicochemical analysis of plants powder was carried out. In this study ash values (total ash, acid insoluble ash and water soluble ash water soluble ash) were determined. The results are shown in table 2.

\section{Extractive values}

Extractive values of Triticum aestivum were determined in methanol, water, chloroform, petroleum ether and benzene and the results are shown in table 3.

\section{Phytochemical screening}

Quantitative phytochemical analysis was performed in aqueous and methanolic extracts and the results showed the presence and absence of certain phytochemicals in the drugs. Phytochemical tests revealed the presence of tannins, saponins, flavanoids, carbohydrates and steroids and results are given in table 4 .

\section{CONCLUSION}

Preliminary phytochemical as well as macroscopic and microscopic characteristics of the plant were studied for quality control of raw drug. The plant of Triticum aestivum exhibits a set of diagnostic characteristics which will help to supplement information in regard to its identification parameters assumed significantly in the way of accepta- 
bility in present scenario of lack of regulatory laws to control the quality of drug. It has been concluded from this study that estimation is highly essential for raw drugs or plant parts used for the preparation of compound formulation of drug. The periodic assessment is essential for quality assurance and safer use of herbal drugs. The drug is promising if the punctiliously selection of variety, its time of collection and identification is done.

\section{REFERENCES}

Anonymous, Pharmacopoeia of India, (1996), Vol II, Govt of India Ministry of health, controller of publication, New Delhi, A-54.

Arya, P., et al.,(2011), Chemoprevention by Triticum aestivum of mouse skin carcinogenesis induced by DMBA and croton oil - association with oxidative status; Asian Pacific Journal of Cancer Prevention, Vol 12 Pages 143-148. PMid: 21517247

Kartesz, JT, (1989), Biota of North America program, Coker Hall Chapel Hill: North Carolina, Pages 27-32.

Khandelwal, K.R., (2010), Practical Pharmacognosy, Techniques and Experiments, edition 20, Nirali Prakashan, Pune, Pages 149-153.

Kohler,GO.,(1944), The effect of stage of growth on the chemistry of the grasses, The Journal of Biological Chemistry, Volume152, Issue2, Page 215-223.

Kokate, CK. Purohit, AP. and Gokhale, (2003), S.B. Text Book Pharmacognosy, edition 25, Nirali Prakashan, Pune.

Kumar S., et al., (2010), Pharmacognostical investigation on wheat grass, International Journal of Pharma and Bio Sciences, Volume 1, Issue 2.
Lai, C., Butler, M., Matney, T., (1980), Mutation Research.,Volume 77, Page 245. [DOI]

Lai, C., Dabney, B., Shaw, C. (1977) Nutrition and Cancer, Volume 1, Page 27. [DOI]

Locniskar, M., (1988), Nutrition and Health Symposium: the University of Texas at Austin, April 1988, Nutrition Today, Volume 23(5), Page 31.

Marwaha, R.K., et al., (2004), Wheat grass juice reduces transfusion requirement in patients with Thalassemia major: A pilot study, Indian Pediatrics, Volume 41, Pages 716-720.

Meyerowitz, S., (1999) Wheat Grass: Nature's Finest Medicine, Edition 6 , Sproutman Publications, Pages 31-33.

Mukherjee, PK., (2010), Quality Control Herbal Drugs, edition1, published by Business Horizons New Delhi, Pages 186-89, 287-90.

Pallavi, K., et al.,( 2011), Pharmacognostic investigation and antibacterial activity of Triticum aestivum, Journal of Pharmacy Research, Volume 4 Issue10, Pages 3355-3359.

Sela, GB., et al.,(2007), Wheatgrass juice may improve hematological toxicity related to chemotherapy in breast cancer patients: A pilot study, Nutrition and Cancer, Volume 58, Issue 1, Pages 43-48. [DOI]

Singh, K, et al., (2010), Effect of Wheatgrass tablets on the frequency of blood transfusions in Thalassemia major; Indian Journal of Pediatrics, Volume 77, Issue 1, Pages 90-91. [DOI]

Trease, GE, Evans, WC., (1996), Pharmacognosy, 15th Edition, New Delhi, WB Saunders Company Ltd., Pages 516-547.

WHO (2002), WHO traditional medicine strategy, World Health Organization, Geneva, Pages 223-225. 